Review

\title{
Massive Open Online Courses
}

\section{Tharindu Rekha Liyanagunawardena}

School of Systems Engineering, University of Reading, Whiteknights, Reading, RG66AY, UK; E-Mail: t.r.liyanagunawardena@reading.ac.uk; Tel.: +44-118-378-8609; Fax: +44-118-975-1994

Academic Editor: Satoshi P. Watanabe

Received: 13 November 2014 / Accepted: 13 January 2015 / Published: 28 January 2015

\begin{abstract}
Massive Open Online Courses (MOOCs) are a new addition to the open educational provision. They are offered mainly by prestigious universities on various commercial and non-commercial MOOC platforms allowing anyone who is interested to experience the world class teaching practiced in these universities. MOOCs have attracted wide interest from around the world. However, learner demographics in MOOCs suggest that some demographic groups are underrepresented. At present MOOCs seem to be better serving the continuous professional development sector.
\end{abstract}

Keywords: massive open online courses; distance education; MOOCs; eLearning

\section{Introduction}

Distance education has a long history; it has evolved with technology changes in the world from using postal services for the delivery of study material to learners and for submission/return of assignments by/to students, through to using each new communication technology: radio, television, video recorders, home computing and the Internet [1]. The Internet and mobile Internet is increasingly adopted by existing higher education providers as a mode of provision and it has supported the emergence of a new model dubbed a massive open online course or MOOC(s) [2].

European Commission defines a MOOC as "an online course open to anyone without restrictions (free of charge and without a limit to attendance), usually structured around a set of learning goals in an area of study, which often runs over a specific period of time (with a beginning and end date) on an online platform which allows interactive possibilities (between peers or between students and instructors) that facilitate the creation of a learning community. As it is the case for any online course, it provides some course materials and (self) assessment tools for independent studying” ([3], p. 2). 
The open online course "Connectivism and Connective Knowledge" (also known as CCK08) led by George Siemens and Stephen Downes offered by the University of Manitoba (Canada) in 2008 is considered the first MOOC [2]. Since its success, a range of both topics and platforms has emerged. Educational institutions as well as learners around the world have shown a remarkable interest in MOOCs. According to The New York Times, 2012 was "the year of the MOOC" with several platform providers associated with prestigious universities, including Coursera (Stanford University) and edX (Harvard University and MIT), emerging. MOOC was also "the educational buzzword of 2012" [4]. By 2013 MOOC was included in the Oxford English Dictionary illustrating the rise of MOOCs within a short span of time since 2008.

There are two main strands of MOOCs identified based on the pedagogy adapted in them. cMOOCs or connectivist MOOCs and XMOOCs or "MOOC as eXtension of something else" [5]. While cMOOCs takes a connectivist approach with co-construction of knowledge as an integral part of the course, xMOOCs (such as Artificial Intelligence Stanford like courses) take a more cognitive-behaviourist approach with more individualist learning [6]. However, in a recent report commissioned by the Higher Education Academy, Bayne and Ross argue that due to the multiple pedagogic forms adopted in MOOCs, the "[b]road-brush descriptions of MOOC pedagogy in terms of a cMOOC/xMOOC binary are no longer representative or particularly useful" ([7], p. 8). They propose thinking about MOOC pedagogy at "micro level of individual course design".

\section{MOOCs and Open Education}

MOOCs are open online courses that generally allow anyone to register and follow the course without a fee (at least for the basic course). Cormier and Siemens [8] argue that they are "a potential by product of open teaching and learning". The level of openness in MOOCs differs from course to course and if the course is offered on a MOOC platform, depending on the platform. While many cMOOCs offered its content using open licensing, other MOOC providers only provide the content for personal use only. For example, the licensing agreement of Coursera, one of the leading xMOOC platforms, states that the material is "only for your own personal, non-commercial use. You may not otherwise copy, reproduce, retransmit, distribute, publish, commercially exploit or otherwise transfer any material, nor may you modify or create derivatives works of the material" [9]. Thus, even though a "by product" of the Open Education movement, MOOCs seem to be less open than Open Education Resources (OERs), freely accessible educational content, which are generally produced with open licensing.

\section{Opportunity for a University Education?}

MOOCs are hailed by many as a solution for the lack of places for university education, especially in the developing world [10]. As many of the courses are offered by prestigious universities (for example, Harvard, MIT and Stanford) one could argue that MOOCs could in fact provide the opportunity to gain a world class educational experience, which until now only privileged few had. However, participant demographics from various MOOC platforms suggest that the large majority of learners accessing these courses already have university degrees. A large scale survey that attracted over 34,000 responses from students from 32 MOOCs offered by the University of Pennsylvania on 
the Coursera platform shows that the large majority of participants $(65.3 \%)$ were from OECD countries [11]. Nearly four out of five (79.4\%) participants had a Bachelor's degree or higher. Significantly more males (59\%) were among the participants. Participants also tended to be young and employed. Similar results were since reported by Ho et al. [12] regarding the participation of the first 17 courses on the edX platform. Only $29 \%$ of the registrants in these courses were female while a mere $2.7 \%$ were from least developed countries. The median of education level across all courses was a Bachelor's degree. Data from the first 21 courses on the FutureLearn platform (as of May 2014) shows that, in contrast to previous findings, the majority of learners $(58 \%)$ on the FutureLearn platform are females [13]. However, similar to Coursera and edX, the large majority of FutureLearn participants too had a university degree or higher educational qualifications (78\%). All these recent and large scale studies show that people who already have a university education comprise majority of MOOCs users. Also very few participants (as a percentage of country's population) from developing countries currently access MOOCs [14] and possible reasons for such observations are discussed by Liyanagunawardena, Williams and Adams [10].

The majority of courses offered as MOOCs are introductory courses that do not require prior knowledge. However, there are specialization tracks provided through MOOCs. For example, Data Science Specialization offered by Johns Hopkins University is a collection of nine MOOCs on the Coursera platform. A recent review of MOOCs on health and medicine that were offered in 2013 has shown that there is a rich variety of courses offered, 98 in 2013, covering various topics from "Fundamentals of Human Nutrition" to "Cardiac Arrest, Hypothermia, and Resuscitation Science" [15]. However, only a minority of them offered college credit or other certification.

The lack of formal recognition for MOOCs could be a reason why they are taken by participants who already have university degrees, because they only need to update their skills as opposed to prove to employers that they have the correct skill set. European Commission report [3] shows that the lack of accreditation is an issue that policymakers should address. More graduates could also be registering on MOOCs because they have better "access" to them than the rest of the population. The author's definition of "access" take a broad view as suggested by van Dijk [16] and Warschauer [17] to include full appropriation of digital technology (including motivational access, material access, skills access, usage access and social, cultural and community support). Furthermore, due to the large cohorts going through the course at a time and small team of educators supporting a course, there is a lack of directed feedback or support for individuals from the course team. However, courses provide Frequently Asked Questions (FAQs) and weekly emails addressing common problems faced by participants, while peer-groups also support each other's learning. From the experience of facilitating three runs of "Begin Programming: build your first mobile game", a FutureLearn course offered by University of Reading, it is seen that a large number of participants expect directed support and are unable to "find their way" when there is an information overload. Some platforms do not support the functionalities/tools for easy navigation of comments and together these may also pose difficulties for learners who are new to the higher educational setting, where self-directed learning is (in many cases for the first time) practiced. However, there is lack of data to gauge whether there is a significant relationship between "completion" of courses and the learners' prior education level. As it stands currently, it seems that MOOCs have not been able to broaden participation in higher education (including students from all socioeconomic regional backgrounds) despite increasing participation (in absolute numbers). 


\section{Lifelong Learning}

The unprecedented pace of change that we see in our contemporary world is largely attributed to the advancement of technologies, globalization, the growth of the knowledge economy and increasing global market competition [18]. Knowledge has become a commodity in this context, especially within the international labor market. The "economic advantage will accrue to countries in which the population acquires competence in processing information into knowledge and applying it in work and everyday life" ([19], p. 17). The redefined workplace in the contemporary world of work requires new ways of working, relying to a significant extent on high skills and expert knowledge [20,21] and "knowledge workers" [22] have gained significance as a major source of labor. When knowledge becomes an increasingly important factor for economic success, to maintain national and individual competitiveness, education, especially at higher levels, is considered vital. Furthermore, due to the rapid rate of knowledge creation, and more importantly, its short shelf-life, there is a growing need for continuous skills updating and lifelong learning [18].

As a knowledge creator and a disseminator, higher education produces knowledge that drives new technological advancements and innovation (for example the World Wide Web). Thus higher education can be seen as an actor which provides impetus for globalization. On the other hand, higher education is also shaped by globalization. With the dawn of the new economy, where knowledge workers gained significance, it is logical to expect a profound impact on higher education [23]. Higher education policies around the world have seen drastic changes in recent years with privatization. One form of privatization is the shift from public educational funding to either cost-recovery methods or cost-sharing methods. Australian higher education institutions charge international students full fees, while charging a reduced percentage to home students; institutions in the UK also practice such a policy towards international students and home/EU students [24]. Committing part of future income in exchange for financing higher education and student loans are other popular schemes that illustrate the shift from institutional financing to student-based financing [24].

In this context, graduating students are heavily in debt and spending more money to upgrade their skills by attending paid for courses become a greater burden for them. At the same time, austerity measures have shrunk training budgets, especially in the government sector. In this environment, MOOCs can be seen as a favorable option for continued professional education. Hoy [25] shows that MOOCs can be a convenient and economical method of continuous medical education, especially given the declining industry funding for professional training. MOOCs can be a good way to continually update one's skillset. For example, a software engineer may have experience in using a/some programming language(s) but for his/her next assignment acquiring skills to program in a different language may be required. In this situation a MOOC could be a useful way to quickly learn the new programming language. Similarly, a medical doctor may want to work with some imaging data for which s/he could use a MOOC such as "Statistical Analysis of fMRI Data" offered by Johns Hopkins University on Coursera to acquire the necessary new skills.

On the other hand, because MOOCs are free for the participants and have no penalties for non-completion, they provide anyone interested in taking a course with a testing ground. Therefore, these could well be used by participants who would want to try new subjects that they never had the chance to explore. MOOCs also provide valuable service to leisure learners. For example, the first run of 
Begin Programming; build your first mobile game FutureLearn course's pre-course survey results showed that $5 \%$ of the participants were 66 years or older. At the end of this course some of these participants thanked the team saying that they had connected with their grandchildren with the "cool" game they had developed and also were able to have a more meaningful conversation with their offspring, who study computing at university [26]. This shows that MOOCs can in fact bridge the generational technology gap and support elderly learners to refresh their skills.

\section{Conclusions}

Despite being a fairly recent phenomenon, massive open online courses, or MOOCs, have attracted wide interest from people around the world. Although they provide the educational opportunities in courses offered by prestigious universities, the lack of recognition and appropriate accreditation is still an issue. MOOCs have attracted thousands of people from all over the world; however, closer inspection of the learner demograraphics suggests that the majority of those served by these courses already have achieved a university education. As such, at present, they seem to be only increasing access to higher education rather than broadening access. Some likely reasons for such observations could be: people with a higher education have better "access" to MOOCs; they are better prepared for the self-learning required in these courses and they are less worried about recognition as opposed to learners without higher educational qualifications who have to "prove" their skills to employers. With the changes in higher education sector funding and austerity measures MOOCs seem to be fulfilling the needs of "knowledge workers" in updating their skills and continued professional development. Therefore, at present MOOCs seem to be better serving the continuous professional development sector. MOOCs can also provide value for leisure learners.

\section{Acknowledgments}

I would like to thank Dr. Ian Daly for his comments and help with proof reading.

\section{Conflicts of Interest}

The author declares no conflict of interest.

\section{References}

1. Denise M. Casey. "A journey to legitimacy: The historical development of distance education through technology." TechTrends 52 (2008): 45-51.

2. Tharindu R. Liyanagunawardena, Andrew A. Adams, and Shirley A. Williams. "MOOCs: A Systematic Study of the Published Literature 2008-2012." International Review of Research in Open and Distance Learning 14 (2013): 201-27.

3. European Commission. "Report on Web Skills Survey: Support Services to Foster Web Talent in Europe by Encouraging the use of MOOCs Focused on web Talent_First Interim Report." May 2014. Available online: http://openeducationeuropa.eu/sites/default/files/MOOCs-for-web-skillssurvey-report.pdf (accessed on 22 January 2015). 
4. John Daniel. "Making Sense of MOOCs: Musings in a Maze of Myth, Paradox and Possibility." Journal of Interactive Media in Education, 2013. Available online: http://jime.open.ac. uk/article/view/2012-18/466 (accessed on 22 January 2015).

5. Stephen Downes. "What the ' $x$ ' in 'xMOOC' Stands for." 9 April 2013. Available online: https://plus.google.com/+StephenDownes/posts/LEwaKxL2MaM (accessed on 22 January 2015).

6. C. Osvaldo Rodriguez. "MOOCs and the AI-Stanford like courses: Two successful and distinct course formats for massive open online courses." European Journal of Open, Distance and E-Learning, 2012. Available online: http://www.eurodl.org/?p=archives\&year=2012\&halfyear= 2\&article $=516$ (accessed on 22 January 2015).

7. Sian Bayne, and Jen Ross. "The pedagogy of the Massive Open Online Course (MOOC): The UK View." Higher Education Academy Report. 2014. Available online: https://www. heacademy.ac.uk/sites/default/files/HEA_Edinburgh_MOOC_WEB_240314_1.pdf (accessed on 22 January 2015).

8. Dave Cormier, and George Siemens. "Through the Open Door: Open Courses as Research, Learning, and Engagement." Educause Review 45 (2010): 30-39.

9. Coursera. "Coursera Terms of Use." 30 October 2014. Available online: https://www.coursera. org/about/terms (accessed on 22 January 2015).

10. Tharindu Liyanagunawardena, Shirley Williams, and Andrew Adams. "The impact and reach of MOOCs: A developing countries' perspective." eLearning Papers, 2013. Available online: http://www.openeducationeuropa.eu/en/article/The-Impact-and-Reach-of-MOOCs:-A-DevelopingCountries\%E2\%80\%99-Perspective (accessed on 27 January 2015).

11. Gayle Christensen, Andrew Steinmetz, Brandon Alcorn, Amy Bennett, Deirdre Woods, and Ezekiel J. Emanuel. "The MOOC Phenomenon: Who Takes Massive Open Online Courses and Why?" Available online: http://papers.ssrn.com/sol3/papers.cfm?abstract_id=2350964 (accessed on 22 January 2015).

12. Andrew D. Ho, Justin Reich, Sergiy Nesterko, Daniel T. Seaton, Tommy Mullaney, Jim Waldo, and Isaac Chuang. "HarvardX and MITx: The First Year of Open Online Courses, Fall 2012-Summer 2013." Available online: http://papers.ssrn.com/sol3/papers.cfm?abstract_id= 2381263 (accessed on 22 January 2015).

13. Simon Nelson. "Updated numbers from our platform." FutureLearn Blog, 27 May 2008. Available online: https://about.futurelearn.com/blog/updated-numbers/ (accessed on 22 January 2015).

14. Sergiy O. Nesterko, Svetlana Dotsenko, Qiuyi Hu, Daniel Seaton, Justin Reich, Isaac Chuang, and Andrew Ho. "Evaluating the geographic data in MOOCs." Available online: http://nesterko.com/ files/papers/nips2013-nesterko.pdf (accessed on 15 January 2015).

15. Tharindu R. Liyanagunawardena, and Shirley A. Williams. "A review of Massive Open Online Courses on health and medicine." Journal of Medical Internet Research 16 (2014): e191. Available online: http://www.jmir.org/2014/8/e191/ (accessed on 22 January 2015).

16. Jan Van Dijk. The Deepening Divide: Inequalities in the Information Society. Thousand Oaks: Sage, 2005.

17. Mark Warschauer. Technology and Social Inclusion: Rethinking the Digital Divide. Cambridge: MIT Press, 2003. 
18. Tharindu R. Liyanagunawardena, Andrew A. Adams, Naz Rassool, and Shirley A. Williams. "Developing government policies for distance education: Lessons learnt from two Sri Lankan case studies." International Review of Education, 2015, forthcoming.

19. United Nations Educational, Scientific and Cultural Organization (UNESCO). Open and Distance Learning: Trends, Policy and Strategy Considerations. Paris: UNESCO, 2002.

20. Phillip Brown, Andy Green, and Hugh Lauder. High Skills: Globalization, Competitiveness and Skill Formation. Oxford: Oxford University Press, 2001.

21. Naz Rassool. Literacy for Sustainable Development in the Age of Information. Clevedon: Multilingual Matters Ltd., 1999.

22. Peter F. Drucker. The Effective Executive. London: Pan Books, 1970.

23. Tharindu R. Liyanagunawardena. "Information Communication Technologies and Distance Education in Sri Lanka: A Case Study of Two Universities.” Ph.D. Thesis, University of Reading, Reading, UK, 2012.

24. N.V. Varghese. "GATS and Higher Education: The Need for Regulatory Policies." Paris: International Institute for Educational Planning, 2007.

25. Matthew B. Hoy. "MOOCs 101: An Introduction to Massive Open Online Courses." Medical Reference Services Quarterly 33 (2014): 85-91.

26. Tharindu R. Liyanagunawardena, Karsten O. Lundqvist, Luke Micallef, and Shirley A. Williams. "Teaching Programming to Beginners in a Massive Open Online Course." Paper presented at OER14: Building Communities of Open Practice, Newcastle, UK, 28-29 April 2014.

(C) 2015 by the author; licensee MDPI, Basel, Switzerland. This article is an open access article distributed under the terms and conditions of the Creative Commons Attribution license (http://creativecommons.org/licenses/by/4.0/). 